\title{
Corrigendum to: "Hypercholesterolemia Prevalence, Awareness, Treatment and Control Among Adults in Malaysia: The 2015 National Health and Morbidity Survey, Malaysia"
}

\author{
Halizah Mat Rifin ${ }^{1}$, Tania Gayle Robert Lourdes ${ }^{1}$, Nur Liana Ab Majid ${ }^{1}$, Hamizatul Akmal Abd Hamid ${ }^{1}$, \\ Wan Shakira Rodzlan Hasani ${ }^{1}$, Miaw Yn Ling ${ }^{1}$, Thamil Arasu Saminathan ${ }^{1}$, Hasimah Ismail ${ }^{1}$, \\ Muhammad Fadhli Mohd Yusoff ${ }^{1} \&$ Mohd. Azahadi Omar ${ }^{1}$ \\ ${ }^{1}$ Institute for Public Health, National Institute of Health, Ministry of Health Malaysia, Jalan Bangsar, Kuala \\ Lumpur, Malaysia \\ Correspondence: Halizah Mat Rifin, Institute for Public Health, National Institute of Health, Ministry of Health \\ Malaysia, Jalan Bangsar, 50590 Kuala Lumpur, Malaysia. Tel: 603-22-979-428. E-mail: \\ halizah.matrifin@moh.gov.my
}

Hypercholesterolemia Prevalence, Awareness, Treatment and Control Among Adults in Malaysia: The 2015 National Health and Morbidity Survey, Malaysia.

doi:10.5539/gjhs.v10n7p11

URL: https://doi.org/10.5539/gjhs.v10n7p11

In the article "Hypercholesterolemia Prevalence, Awareness, Treatment and Control Among Adults in Malaysia: The 2015 National Health and Morbidity Survey, Malaysia" which appeared in Volume 10, No. 7(2018), a sentence in the abstract under results section, "Only a mere 12.7\% (95\% CI:12.4 -13.1) among those who were aware were on treatment and out of which only $53.7 \%$ (95\% CI: 50.1-57.2) had their cholesterol levels controlled" appeared incorrect and should have appeared as "Only a mere 12.7\% (95\% CI:12.4 -13.1) were on treatment and out of which only $53.7 \%$ (95\% CI: 50.1-57.2) had their cholesterol levels controlled".

We apologise to the readers of Global Journal of Health Science for this error.

\section{Copyrights}

Copyright for this article is retained by the author(s), with first publication rights granted to the journal.

This is an open-access article distributed under the terms and conditions of the Creative Commons Attribution license (http://creativecommons.org/licenses/by/4.0/). 